\title{
Increase in scarlet fever notifications in the United Kingdom, 2013/2014
}

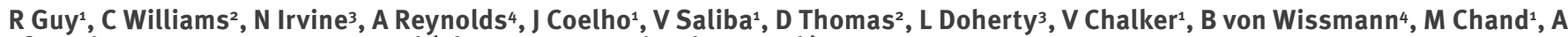
Efstratiou ${ }^{1}$, M Ramsay ${ }^{1}$, T Lamagni (Theresa.Lamagni@phe.gov.uk) ${ }^{1}$

1. Public Health England, London, United Kingdom

2. Public Health Wales, Cardiff, Wales, United Kingdom

3. Public Health Agency, Belfast, Northern Ireland, United Kingdom

4. Health Protection Scotland, Glasgow, United Kingdom

Citation style for this article:

Guy R, Williams C, Irvine N, Reynolds A, Coelho J, Saliba V, Thomas D, Doherty L, Chalker V, von Wissmann B, Chand M, Efstratiou A, Ramsay M, Lamagni T.

Increase in scarlet fever notifications in the United Kingdom, 2013/2014. Euro Surveill. 2014;19(12):pii=20749. Available online: http://www.eurosurveillance.org/ ViewArticle.aspx?Articleld $=20749$

Article submitted on 24 March 2014 / published on 27 March 2014

Increases in scarlet fever above usual seasonal levels are currently being seen across the United Kingdom. Medical practitioners have been alerted to the exceptional increase in incidence. Given the potential for this to signal a population increase in invasive group A streptococcal disease, close monitoring of invasive disease is essential.

\section{Scarlet fever notifications September 2013 to March 2014}

In the United Kingdom (UK), statutory notifications of scarlet fever are submitted to local health protection teams in England, Wales and Northern Ireland. Diagnosis is based on clinical symptoms consistent with scarlet fever, with or without laboratory confirmation of group A streptococcal (GAS) infection. A total of 3,752 notifications of scarlet fever have been made so far this season (week 372013 to week 11 2014) compared with total notifications ranging from 1,565 to 2,868 in the seasons from 2008/09 to 2012/13 (Figure 1). A total of 635 notifications have been received across England, Wales and Northern Ireland in week 11 of 2014 .

The increase in scarlet fever has been seen across most parts of the UK with the highest rate of notifications per 100,000 population reported in Cheshire and Merseyside (13.0), East Midlands (11.9), Avon Gloucestershire and Wiltshire (10.6), Thames Valley

\section{FIGURE 1}

Weekly notifications of scarlet fever, England, Wales and Northern Ireland, 8 September 2008-16 March 2014

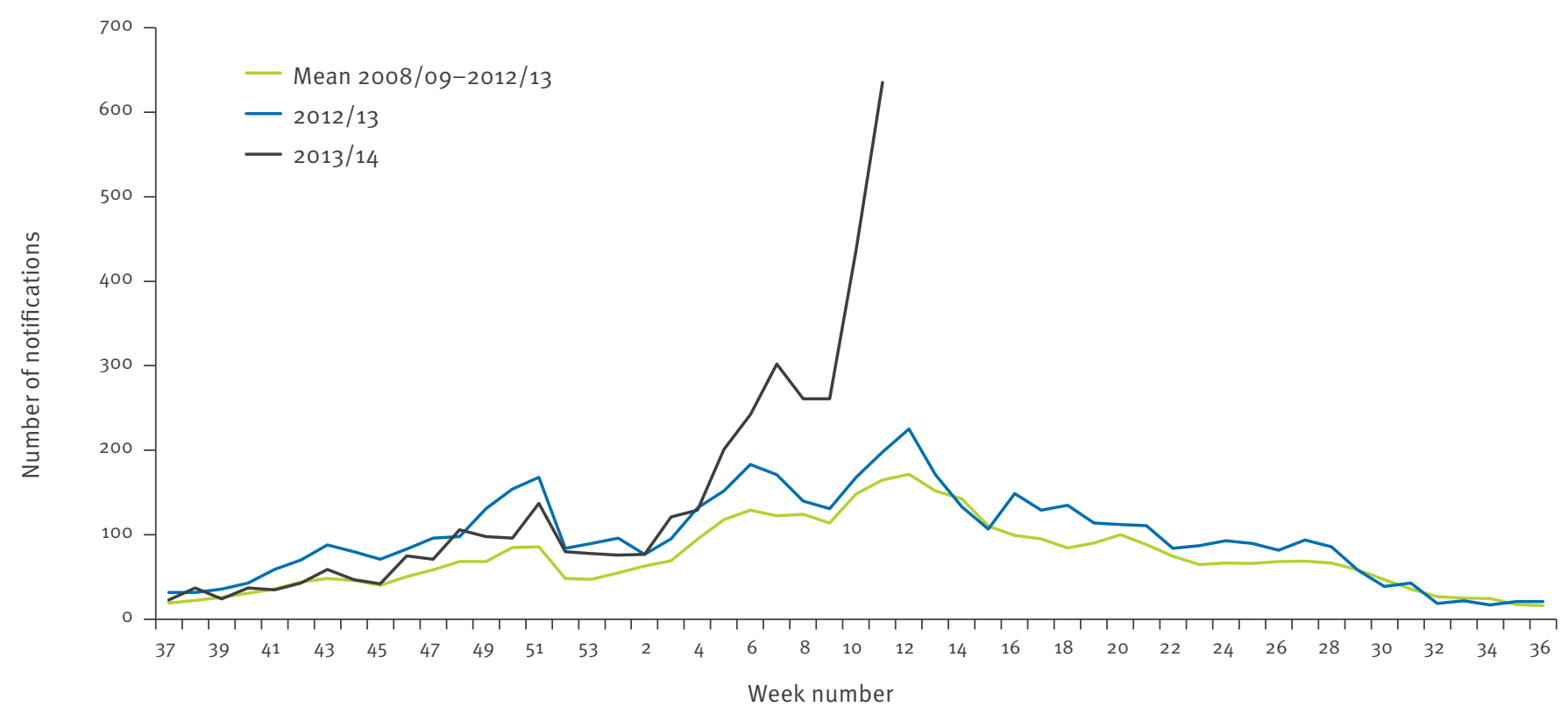


Rate per 100,000 population scarlet fever notifications in England, Wales and Northern Ireland, 9 September 2013-16 March 2014

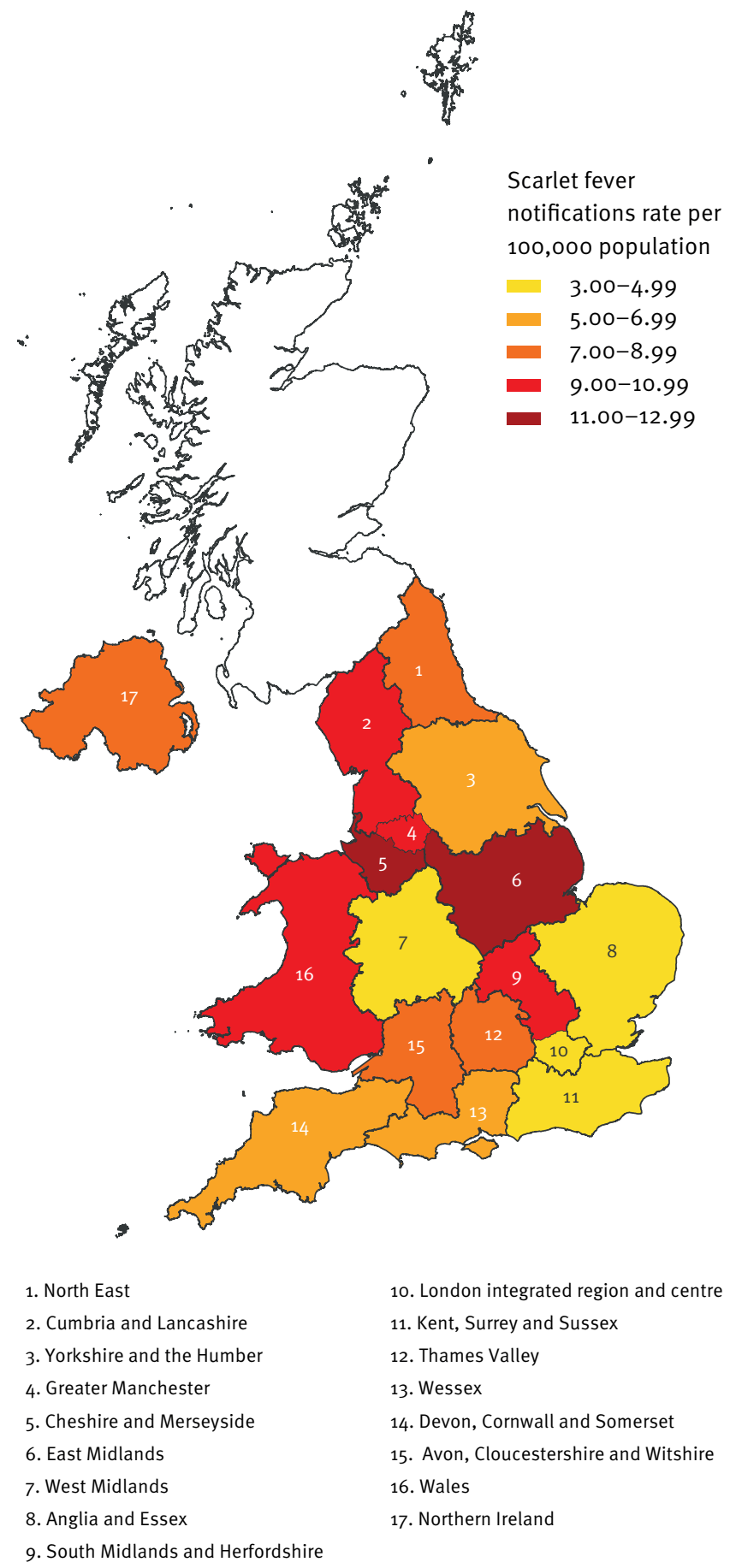

The period in weeks to which the map refers is from week 372013 to week 112014 .

(9.5), North East (9.7) and Northern Ireland (9.2) (Figure 2).

The age and sex distribution of cases notified in England to date for this season remains similar to previous years, with $87 \%$ of cases reported in children under 10 years of age (median: 4 years; range: $<1-90$ years) and only $5 \%$ reported in adults ( $\geq 18$ years-old; $36 \%$ male $(63 / 175)$. Outbreaks in schools have been reported in several parts of the UK $[1 ; 2]$.

\section{Invasive group A streptococcal infection}

Cases of invasive GAS (iGAS) infection, defined as the isolation of GAS from a normally sterile site, are identified through national routine laboratory surveillance. Microbiology laboratories report diagnoses electronically to Public Health England (England, Wales and Northern Ireland) and Health Protection Scotland respectively. Reporting of iGAS infection is notifiable in England, Wales and Scotland but not in Northern Ireland. A total of 807 iGAS cases in the UK were identified through routine surveillance between week 37 2013 and week 11 2014, a slight increase on the mean (784 reports) but within the range (692-881 reports) for the same period in the previous four years (Figure 3). The median age of cases was 59 years (range: <1-102 years), similar to previous years. The proportion of iGAS cases who were male, 42\% (303/713), was slightly lower than in recent years, $49 \%$ to $53 \%$ for $2009 / 10$ to $2012 / 13$. Given delays inherent within routine laboratory reporting, further reports for the first few weeks in 2014 can be expected.

Overall, $6 \%(26 / 471)$ of iGAS isolates reported this season (England, Wales and Northern Ireland) were reported as erythromycin-resistant. There have been no reports of penicillin resistance in iGAS isolates in the UK to date.

Assessment of iGAS isolates referred to the Public Health England national reference laboratory in London has not identified any unusual emm types so far this season. The proportion of strains identified as emm3 increased in February $(23 \% ; 32 / 141)$ when compared to January $(16 \% ; 24 / 152)$.

\section{Discussion}

Scarlet fever incidence has shown a remarkable increase this season. Previous analysis of scarlet fever notifications in England over the last century suggest cyclical patterns of incidence, with resurgences occurring on average every four years [3]. The last peak year for scarlet fever was 2008/09, with incidence of invasive disease tending to mirror those of superficial manifestations of GAS infection in many but not all years [4]. While the enhanced media coverage and public health alerts may have increased case ascertainment during this season, the escalation prior to this suggests a genuine increase in disease incidence. The reasons behind this increase are unclear but may be attributable to a natural cycle in disease incidence.

It remains possible that the increase or part of the increase is attributable to changes in virulence of circulating strains or increased incidence in particular risk 


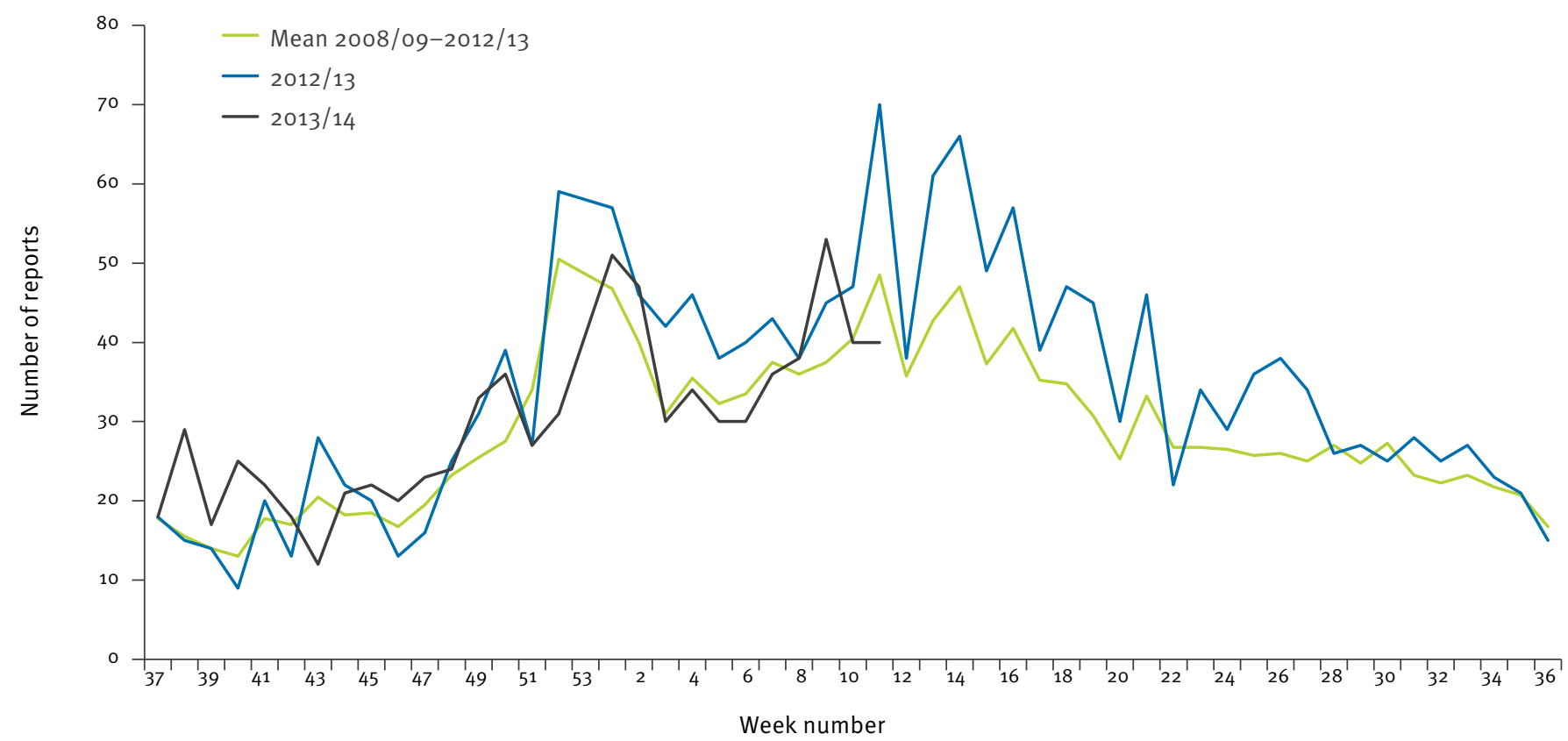

groups. An exceptional increase in scarlet fever incidence in Hong Kong during 2011 and 2012 was attributed to the introduction of a new emm12 strain [5]. Continued vigilance for the emergence of a novel strain or changes in pattern of clinical disease is essential.

At present, antimicrobial susceptibility results are not indicating any change in antibiotic susceptibility [6]. Analysis of isolates originating from normally sterile sites, which were submitted to the national reference laboratory, has not identified any unusual types circulating, although a slight increase in the proportion of due to emm3 is currently being observed. Strains harbouring this emm type were implicated in the UK rise in incidence in scarlet fever and iGAS infection during 2008/09 [7], and also implicated in population increases in iGAS infection incidence in Ireland in 2013 [8]. While the current rise in emm3 is slight, it raises some concern given its association with a higher case fatality rate than other emm types [9;10]. Rapid assessment of changes in case fatality rate will assist in monitoring any such changes during the current season.

As a result of the current rise in scarlet fever notifications, clinicians, microbiologists and health protection specialists across Europe should continue to be mindful of potential increases in invasive disease and maintain a high index of suspicion in relevant patients, as early recognition and prompt initiation of specific and supportive therapy for patients with iGAS infection can be life-saving. Alerts have been issued by local health protection staff to frontline medical staff in the UK. An unusual pattern of outbreaks of scarlet fever has also been noted in Belgium during this season (K Loens, personal communication, March 2014). Comparison of strains across the two countries would be beneficial in understanding the current situation in the UK.

Acknowledgments

We thank the local and regional health protection staff and microbiologists for their rapid provision of information concerning incident cases.

Conflict of interest

None declared.

Authors' contributions

All authors reviewed and approved the manuscript. RG drafted the manuscript and analysed the data presented. A Reynolds, B von Wissman extracted and analysed data for Scotland. C Williams and D Thomas extracted and analysed data for Wales. N Irvine and L Doherty extracted and analysed data from Northern Ireland. R Guy and T Lamagni extracted data for England and collated and analysed UK wide data. V Chalker, A Efstratiou, V Chalker and J Coelho were responsible for microbiological analysis of submitted isolates and analysis of typing data. M Chand reviewed all analyses and edited the manuscript. T Lamagni provided oversight to the manuscript submission and Mary Ramsay to associated public health communications. 


\section{References}

1. ProMED-mail. Streptococcus, group A, scarlet fever - UK (04): (Scotland) request for information. Archive Number 20140306.2317827. 06 Mar 2014. Available from: http://www. promedmail.org/direct.php?id=2317827

2. ProMED-mail. Streptococcus, group A, scarlet fever - UK (06): (England), request for information. Archive Number 20140320.2344345. 20 Mar 2014. Available from: http://www. promedmail.org/direct.php?id=2344345

3. Lamagni TL, Dennis J, George R, Efstratiou A. Analysis of epidemiological patterns during a century of scarlet fever. European Scientific Conference on Applied Infectious Disease Epidemiology; 2008 Nov; Berlin, Germany.

4. Lamagni TL, Efstratiou A, Dennis J, Nair P, Kearney J, George R. Increase in invasive group A streptococcal infections in England, Wales and Northern Ireland, 2008-9. Euro Surveill. 2009;14(5). pii: 19110.

5. Luk EY, Lo JY, Li AZ, Lau MC, Cheung TK, Wong AY et al. Scarlet fever epidemic, Hong Kong, 2011. Emerg Infect Dis. 2012;18(10):1658-61.

http://dx.doi.org/10.3201/eid1810.111900

6. Public Health England (PHE). Voluntary surveillance of pyogenic and non-pyogenic streptococcal bacteraemia in England, Wales and Northern Ireland: 2012. London:PHE;2013. Available from: http://www.hpa.org.uk/webc/HPAwebFile/ HPAweb_C/1317140271938

7. Health Protection Agency (HPA). Group A streptococcal infections: third update on seasonal activity, 2008/09. Health Protection Report. 2009;3(13). Available from: http://www.hpa. org.uk/hpr/archives/2009/news1309.htm\#igas3

8. Meehan M, Murchan S, Bergin S, O'Flanagan D, Cunney R. Increased incidence of invasive group A streptococcal disease in Ireland, 2012 to 2013. Euro Surveill. 2013;18(33):20556.

9. Lamagni TL, Neal S, Keshishian C, Powell D, Potz N, Pebody R et al. Predictors of death after severe Streptococcus pyogenes infection. Emerg Infect Dis. 2009;15(8):1304-7. http://dx.doi.org/10.3201/eid1508.090264

10. O'Loughlin RE, Roberson A, Cieslak PR, Lynfield R, Gershman $\mathrm{K}$, Craig A et al. The epidemiology of invasive group $\mathrm{A}$ streptococcal infection and potential vaccine implications: United States, 2000-2004. Clin Infect Dis. 2007;45(7):853-62. http://dx.doi.org/10.1086/521264 